УДК 37.012

\title{
Л.В. Неклюдова
}

\section{СОЗДАНИЕ УСЛОВИЙ РАЗВИТИЯ ЭТНИЧЕСКОЙ ТОЛЕРАНТНОСТИ УЧАЩИХСЯ В НОРЬИНСКОЙ ШКОЛЕ}

В статье дано теоретическое обоснование и приведен опыт практического применения знаний по развитию этнической толерантности учащихся в условиях международного школьного сотрудничества в удмуртской сельской школе. Для многонациональной и поликультурной Удмуртии эта проблема особенно актуальна. На селе наблюдается возрастание социальных проблем, которые приводят к снижению уровня культуры населения. От деятельности сельских школ будет во многом зависеть положительность социальных изменений. Понятие «толерантность» рассматривается с различных позиций, обосновываются условия ее развития в школе, приведены составляющие толерантной среды. Для развития этнической толерантности подростков в школе необходимо создавать условия по изучению иных национальных и культурных традиций. Однако чтобы подростки понимали и изучали культуру другого народа, нужно, в первую очередь, чтобы они хорошо знали и понимали культуру своего народа, историю родной местности, поселка, деревни, а потом уже сравнивали культурные традиции разных народов, находили в них общее и различия («Уважай другого, умея уважать себя»). Статья содержит описание практического опыта развития этнической толерантности учащихся в условиях международного школьного сотрудничества в школе с. Норья. Село около 20 лет сотрудничает с поселениями в странах финноугорского мира, которые занимаются краеведением и, шире, возрождением и сохранением культуры своих народов. Положительные изменения наблюдаются не только в самой школе, подобная деятельность дает мощный толчок к развитию и процветанию села.

Ключевые слова: терпимость, толерантность, этническая толерантность, сознание, идентичность, толерантная среда, условия развития этнической толерантности в сельской школе, школа-партнер.

DOI: $10.35634 / 2412-9550-2019-29-3-345-349$

В условиях расширяющейся глобализации, с увеличением масштабов взаимодействия разных стран в различных сферах жизнедеятельности обостряется противостояние между народами, что, в свою очередь, провоцирует дестабилизацию в обществе, рост агрессии и нетерпимости. Проблема этнической толерантности в связи с этим является необходимым аспектом межкультурной коммуникации и межэтнического взаимодействия как в мире, в России, так и в нашем регионе. Удмуртская Республика многонациональна, в ней проживают представители различных культур, поэтому проблема толерантности выступает основным принципом и безусловным гарантом политической, экономической и социокультурной стабильности региона.

В педагогике рассматривается понятие этическая толерантность, которая понимается как «способность человека проявлять терпение к малознакомому образу жизни представителей других этнических общностей, их поведению, национальным традициям, обычаям, чувствам, мнениям, идеям, верованиям и т. д.» [1. С. 302-303].

В Удмуртской Республике многие образовательные учреждения вовлечены в различные проекты межкультурного взаимодействия и международного сотрудничества в области образования. Весной 2009 г. группа учителей средней общеобразовательной школы с. Норья Малопургинского р-на начали сотрудничать с финской школой д. Селкие.

Преподаватели школы и совет д. Селкие размышляли над тем, каким образом заинтересовать детей изучением истории деревни и тем, что с ней связано. Таким образом, в Селкие появился проект «Сельская школа - сердце села», направленный на изучение топонимики деревни и, шире, - возрождение культурных традиций края. К нему присоединилась общеобразовательная школа с. Норья, которая работала по родственному проекту «Культурное наследие», нацеленному на сохранение и возрождение культурного наследия удмуртского и финского народов. Он предполагал сбор и сравнение фактов, данных о традиционных культурах удмуртов и финнов и их статистическую обработку. Позднее к ним подключилась начальная школа пос. Уналаклиит (Аляска, США), которая также вела у себя подобную деятельность.

Норья имеет богатую историю и крепкие традиции. Впервые в документах селение упоминается в Ландратской перписи 1716 г., которая также приводила данные 1710 г.: в 1710 г. в д. Большей Нырье 
насчитывалось 33 двора, в 1716 г. - 32 двора и 146 чел. [9. Л. 356-361]. С большой долей вероятности можно предполагать существование такого большого по тем временам поселения в XVII в., может быть - и ранее. Начиная с реформ П.Д. Киселева 1837-1841 г., оно, уже в статусе села, становится центром Большенорьинской волости (Сарапульский уезд), с территориальными изменениями просуществовавшей вплоть до первых лет Советской власти [10. Л. 1об.-20; 11. С. 257; 12. С. 86]. Население этого района в основном селилось на берегах рек Постолка, Лудзя, Сизяшурка и Уйвайка. Последняя из них протекает по центру села, разбивая его, таким образом, на две части. Сами жители называют речку Улвайка, так как ее исток очень похож на ветвистое деревце («уло-ваё писпу кадь»).

В 1973 г. в 3 км от Норьи был обнаружен Покровский могильник - памятник эпохи Раннего средневековья, расположенный на левом берегу р. Сизяшурки, правом притоке р. Постолки (та, в свою очередь, является правым притоком р. Иж). В некоторых погребениях обнаружили крючки, в основном выполненные из железа и бронзы. Конструкция их почти однотипна: один конец стержня загнут под углом, другой - в петлю треугольной или овальной формы. Длина крючков $-3,5-9,5$ см.

Изучая научную литературу по истории Удмуртии, участники проекта заметили, что в ней скудно дается описание способов рыбной ловли древними удмуртами. Вместе с тем в реках и речушках региона водились ценные породы рыб (стерлядь, осетр, белуга) и «сорная» рыба (лещь, линь, судак, щука, язь и др.). Следовательно, неизбежно должны были существовать разнообразные традиционные способы рыбной ловли.

В рамках проекта «Культурное наследие» упор делался на изучение традиционных способов рыбной ловли. В нем были заняты ученики 5-7 классов трех деревень: Норья, Кулаево, Сизяшур. Ученики работали под руководством преподавателя школы Елены Юрьевны Королевой. В работе проекта выяснилось, что большинство снастей удмуртов были самодельными. Ловили удочками (визнан), бреднями (калтон), сачками (сак), сетями (сеть), «люлькой», а самые маленькие дети обычными бабушкиными платками и самоткаными половиками. Устраивались самоловные снастиморды, верши (мурдо). Наиболее распространена была ловля сетями, дававшая большой эффект при малой затрате времени. Сети вязались из сученых конопляных ниток, морды плелись из прутьев. Саками обычно ловили рыбу весной, когда спадал паводок и та поднималась на нерест. Удочками, бреднями, мордами и сетями больше рыбачили летом и ранней осенью. Остроги в основном использовали осенью для ночного лова, когда вода становилась прозрачной, а рыба - менее подвижной. Как источник света использовали смолистые сухие дрова или фонарь, которые укрепляли на носу лодки в специальной железной решетке. Один рыбак, сидя на корме, медленно и осторожно вел лодку, другой, стоя на носу, бил острогой спящую рыбу. Во время рыбалки часто пользовались ботом - приспособлением для вспугивания рыбы, спрятавшейся среди камышей, ветвей или коряг. Полученный материал был обобщен в статье Е.Ю. Королевой и А. Дюргета (Alla Durget) «Сравнительный анализ культурных традиций удмуртского и финского народов» [3]. Кроме того, был составлен список рыб, обитающих в наших речках и прудах (как правило, искусственных). Например, детей заинтересовало удмуртское название линя - «тыпарсь», что в дословном переводе означает «озерная свинья» (получил он такое название от своей особенности закапываться в речное, озерное дно). По собранным материалам была создана презентация, которая демонстрировалась на семинарах и конференциях, их также опубликовали в сборнике, изданном в Финляндии [7].

В свою очередь, финские ребята составили годовой календарь промысла рыб, сделали рисунки о традиционных способах рыбной ловли. Но самое важное, что при поддержке главы поселения Селки Теро Мустонена, был возрожден один из способов зимней рыбалки неводом, не практиковавшейся в течение 70 лет. В этом историческом событии участвовало всё взрослое население, а выловленную ряпушку по традиции поровну поделили между всеми жителями деревни.

Сравнивая традиционные способы рыбной ловли финнов и удмуртов, можно говорить о том, что в Финляндии распространены коллективные способы рыбной ловли, поскольку это озерная страна. Размеры их снастей превосходят снасти удмуртов. У удмуртов в равной мере можно наблюдать и коллективное, и одиночное рыболовство. Однако способы рыбной ловли и снасти очень схожи. По мнению Е.Ю. Королевой и А. Дюргета, это - одно из неоспоримых подтверждений родства двух народов [3]. В свою очередь, заметим, на данную схожесть оказал факт проживания примерно в одинаковых природных условиях (умеренный климат, изобилие водных источников и т. д.).

Несомненно, изучение элементов традиционной культуры, быта, хозяйственной деятельности воспитывает уважение к собственной истории и культуре. В ходе живого общения с хранителями ин- 
формации происходит передача жизненного опыта из поколения в поколение, а собранный материал становится источником дополнительной информации для следующих исследований, что может стать в самое ближайшее будущее началом для возрождения культурных традиций.

В рамках международного проекта педагоги и ученики удмуртской и финской школ регулярно общались между собой в режиме онлайн. Учителя и школьники Норьинской школы несколько раз посещали финскую школу Селкие, а финские педагоги и ученики - Норью. Преподаватели, участники проекта, обобщали полученный опыт в научных сборниках, издаваемых в Финляндии [4-6]. Американские коллеги, подключившись к совместной работе последними, в большей степени находятся в стадии исканий.

С целью формирования мотивации к межкультурному сотрудничеству, умения организовывать совместную деятельность в условиях диалога культур в рамках совместного проекта были проведены такие мероприятия, как веб-конференция «Рождественские встречи», школьные исследовательские проекты «Традиционные способы рыбной ловли», «Топонимические названия своего населенного пункта», веб-встреча с преподавателями и жителями с. Норья, д. Селкие и пос. Уналаклиит. Также проводились совместные видео-педсоветы, семинары, отчетные концерты, выставки и другие мероприятия. Для формирования ценностного отношения к иной культуре и воспитания этнической толерантности финских и российских школьников знакомили между собой, разучивали с ними традиционные игры, танцы удмуртского и финского народов. Дети участвовали в мастер-классах по приготовлению национальных блюд (щекера и перепечи), знакомились с обычаем празднования Пасхи и разукрашивания деревянных пасхальных яиц, посетили национальный центр декоративно-прикладного искусства и ремесел Удмуртской Республики и Удмуртский республиканский краеведческий музей имени К. Герда.

Важным условием формирования этнической толерантности в условиях проекта была позиция педагога, его педагогические умения, ценностные ориентиры, система отношений к людям как носителям разных этнокультур, умение вводить учащихся в мир человеческих отношений, воздействовать на формирование системы ценностей детей, обеспечивать условия для совместной конструктивной активности школьников. Поэтому большое значение в международном проекте уделялось повышению квалификации педагогов, которое опиралось на принципы непрерывности, целостности и обладало адаптивными свойствами. Такая система помогает педагогам освоить современные ценностносмысловые отношения (ориентации, установки, убеждения), основополагающими идеями ее стали идеи демократизма, гуманизма, нравственности, глобального мировосприятия, диалогичности общения, плюрализма мнений [7; 8].

Создание толерантной среды в условиях международного сотрудничества сельской школы во многом будет зависеть от деятельности педагогического коллектива, от его ценностно-смысловых отношений (ориентаций, установок, убеждений) [6]. Педагоги школы должны уметь строить толерантные отношения, хорошо владеть приемами интерактивного обучения, грамотно управлять исследовательской активностью ученика, а также быть включенными в профессиональное взаимодействие с педагогами школы-партнера. Профессиональное взаимодействие складывается из совместного проведения веб-мероприятий (педагогических советов, совещаний, семинаров, конференций, конкурсов и др.) и непосредственного посещения педагогами школ-партнеров. Основываясь на выше сказанном, можно предположить, что основными составляющими толерантной среды в условиях международного сотрудничества сельской школы будут:

1. Организация исследовательской деятельности среди подростков и детей по изучению истории поселения (села, деревни), возрождение и сохранение культурных традиций своего народа и сравнение их с культурами родственных / других народов. Она может проявляться в проведении поисково-исследовательского лагеря, конференций исследовательских и проектных работ, отчетных выставок и концертов и др.;

2. Организация обучающей деятельности для учителей школ и педагогов дополнительного образования по продвижению идей развития этнической толерантности подростков через изучение истории поселения и сравнения национальных культурных традиций с культурами других народов (круглых столов, обучающих семинаров, тренингов и др.).

Педагогами Норьинской школы был организован круглый стол по теме «Межкультурное взаимодействие в образовательных учреждениях Удмуртии: опыт международного сотрудничества и перспективы развития». Круглый стол проходил с включением веб-трансляции педагогов и учащихся школ Селкие (Финляндия) и Уналаклиит (Аляска, США). На нем выступили студенты и ученики из 
Германии, Франции, Италии, Таиланда (участники программ по обмену), а также педагоги школ и других образовательных и научных учреждений. На круглом столе отметили насущность подобных обсуждений и высказались за необходимость проведения таких регулярно мероприятий.

Для реализации цели и задач проекта отбирались средства, позволяющие вовлечь учащихся в процесс принятия решения в реальных жизненных ситуациях. В частности, его наработки использовались в таких учебных дисциплинах, как история, география, удмуртский язык и литература, музыка, технология, краеведение, английский язык. Были организованы «фестиваль», конкурс танцев народов мира, конкурс «Удмурт батыр», дни родного языка, на которых формировались навыки ведения диалога, развивалась эмоциональная устойчивость и гибкость. Использовались методы проектов, незаконченных историй, моделирования ситуаций, содержащие проблему межэтнического взаимодействия. Познавательная, исследовательская деятельность расширяла кругозор, знания учащихся об этнокультурных особенностях, культурных традициях своего и иного народа. Народные игры и танцы заставляли ощущать общность интересов. Использованию усложняющихся ситуаций, стимулирующих толерантное отношение к представителям разных этносов, способствовала экологическая и туристическая деятельность.

Подводя общий итог международного сотрудничества Норьинской школы, нужно обязательно обратить внимание на влияние образовательного учреждения на развитие села в целом. Школа на селе - не только очаг культуры и досуга, она дает толчок, способствует развитию и процветанию села. За период внедрения проекта «Культурное наследие» в с. Норья село изменилось в лучшую сторону. Это видно по чистоте улиц, преображении частных строений и усадеб, летом все село украшено цветами, зимой регулярно чистятся улицы и проезды. Деятельность по международному сотрудничеству в Норье не останавливается, открываются новые его горизонты, проект переходит на другой уровень, педагоги школы сейчас активно делятся своим опытом на различных семинарах и конференциях. Очень бы хотелось, чтобы как можно больше сельских, да и городских школ приобщались к подобным проектам, это, несомненно, будет способствовать стремительному ускорению положительных изменений в нашей республике.

\section{СПИСОК ЛИТЕРАТУРЫ}

1. Бойко В.В. Энергия эмоций в общении. М.: Филинъ, 1996.

2. Бондарева Г.Н. Формирование толерантной личности школьника // История. 2002. № 20. С. 13-14.

3. Королева Е.Ю., Durget Alla. Сравнительный анализ культурных традиций удмуртского и финского народов // Высшее образование в XXI веке: II Междунар. науч.-практ. конф., г. Ижевск. Киров: изд-во ВятГГУ, 2012. C. 211-217.

4. Mustonen Tero. Selkien luonnosta ja perinteestä. PrioRita, 2009. № 1.

5. Mustonen Tero. Selkien perinteestä ja luonnosaa. PrioRita, 2010. № 2.

6. Mustonen Tero. Selkien perinteestä ja luonnosaa. PrioRita, 2012. № 4.

7. Неклюдова Л.В. Особенности организации непрерывной курсовой подготовки педагогов в системе повышения квалификации педагогов // Фундаментальные исследования. 2012. № 11 (часть 6). С. 1395-1399.

8. Неклюдова Л.В. От творчества педагога - к творчеству ребенка: Методические рекомендации. Ижевск: Издво ИПК и ПРО УР, 2004.

9. Подворная («Ландратская») перепись 1716 г. // Удмуртское Прикамье по писцовым описаниям и подворным переписям XVII - начала XVIII веков [Электронный ресурс] / автор-сост. В.С. Чураков. Ижевск: УИИЯЛ УрО РАH, 2009.

10. ГАКО. Ф. 176. ОП. 2. Д. 1315.

11. Пислегин Н.В. Удмуртское крестьянство и власть (конец XVIII - первая половина XIX в.). Ижевск: УИИЯЛ УрО РАН, 2010.

12. Справочник по административно-территориальному делению Удмуртии. 1917-1991 гг. Ижевск: Удмуртия, 1995.

Поступила в редакцию 31.01.2019

Неклюдова Людмила Викторовна, кандидат педагогических наук, доцент, доцент кафедры педагогики и психологии

ФГБОУ ВО «Глазовский государственный педагогический институт имени В.Г. Короленко»

42762, Россия, Удмуртская Республика, г. Глазов, ул. Первомайская, 25

E-mail: nekludovalv@rambler.ru 


\section{L.V. Neklyudova}

CREATION OF CONDITIONS FOR THE DEVELOPMENT OF ETHNIC TOLERANCE OF SCHOOL CHILDREN IN THE NORYA VILLAGE

DOI: $10.35634 / 2412-9550-2019-29-3-345-349$

The article gives theoretical substantiation and experience of practical application of knowledge on development of ethnic tolerance of pupils in the conditions of the international school cooperation in an Udmurt rural school. For multinational and multicultural Udmurtia this problem is particularly relevant. In villages there is an increase in social problems, which lead to a decrease in the level of culture of the population. The success of social changes will largely depend on the activities of rural schools. The concept of "tolerance" is considered from different positions, the conditions of its development in school are substantiated, and the components of the tolerant environment are given. For the development of ethnic tolerance of adolescents in school, it is necessary to create conditions for the study of other national and cultural traditions. However, in order for teenagers to understand and study the culture of another people, it is necessary, first of all, that they know and understand the culture of their people, the history of their native area, village, and then compare the cultural traditions of different peoples, find common and differences in them ("Respect the other, being able to respect yourself"). The article describes the practical experience of the development of ethnic tolerance of students in the conditions of international school cooperation in the school of village Norya. The village has been cooperating with settlements in the Finno-Ugric countries for about 20 years, which are engaged in local history and, more broadly, the revival and preservation of the culture of their peoples. Positive changes are observed not only in the school itself; such activities give a powerful impetus to the development and prosperity of the village.

Keywords: tolerance, ethnic tolerance, consciousness, identity, tolerant environment, conditions of development of ethnic tolerance in rural school, partner school.

Received 31.01.2019

Neklyudova L.V., Candidate of Pedagogy, Associate Professor, Associate Professor at Department of pedagogy and psychology Glazov State Pedagogical Institute named after V.G. Korolenko Pervomayskaya st., 25, Glazov, Udmurt Republic, Russia, 427621 E-mail: nekludovalv@rambler.ru 